\title{
\#EdTechHub
}

Realising the potential of technology in education

\section{Pakistan Distance-Learning Topic Brief: Primary-level Deaf Children}

Paul Lynch, Tom Kaye, Emmanouela Terlektsi.

EdTech Hub, https://edtechhub.org Helpdesk Request Response No. 16

2020-06-16

DOI: 10.5281/zenodo.3891379 


\section{About this document}

Recommended Paul Lynch, Tom Kaye and Emmanouela Terlektsi (2020). Pakistan citation. Distance-Learning Topic Brief: Primary-level Deaf Children. (EdTech Hub Helpdesk Response No 16) DOI: 10.5281/zenodo.3891379. Available at https://docs.edtechhub.org/lib/LP4PGMNA. Available under Creative Commons Attribution 4.0 International, https://creativecommons.org/licenses/by/4.0/.

Licence.

Creative Commons Attribution 4.0 International https://creativecommons.org/licenses/by/4.0/. You - dear readers - are free to share (copy and redistribute the material in any medium or format) and adapt (remix, transform, and build upon the material) for any purpose, even commercially. You must give appropriate credit, provide a link to the license, and indicate if changes were made. You may do so in any reasonable manner, but not in any way that suggests the licensor endorses you or your use.

Identifiers. $\quad$ 2405685:LP4PGMNA; $10.5281 /$ zenodo.3891379

Internal use. g/d/1Sg591UAl-oXPV kfiL3FmDOTHQ mTj6 aoiSZ9ESk8g/

Version 1

Reviewers: Björn Haßler, Caitlin Moss Coflan

For enquiries please email helpdesk@edtechhub.org. 
1. Introduction $\quad 4$

1.1. Methods 4

1.2 Background information about deafness 5

1.3 Use of terminology $\quad 6$

1.4 Communication of deaf children $\quad 6$

1.5 Impact of deafness on language and learning 7

1.6 Deaf students and distance learning 8

2. Pakistan context 9

2.1 Child deafness in Pakistan $\quad 9$

2.2. National government policy on special education in Pakistan 9

2.3 School provision for deaf children 10

2.4 Distance learning for deaf children in Pakistan 10

3. Discussion of distance-learning solutions for deaf children 12

3.1 Hardware and equipment for distance learning 12

3.2 Software for distance learning 13

3.3 Delivery mediums for distance learning $\quad 14$

3.4 Accessibility of distance learning 14

3.5 Monitoring and evaluating distance learning for deaf children 16

3.6 Examples of international projects responding to Covid-19 for deaf children 18

4. Recommendations $\quad 20$

5. Resources $\quad 24$

5.1 Organisations providing information about deaf education 24

5.2 Guidance on accessibility of distance learning resources 24

5.3 Accessible information for children for COVID -19 24

5.4 Helpful guidance notes on inclusive digital learning 24

5.5 Online resources / stories for deaf children 24

$\begin{array}{ll}5.6 \text { Evaluation criteria for programmes } & 24\end{array}$

6. References $\quad 25$ 


\section{Introduction}

The COVID-19 crisis has severely impacted the ability of national education actors to provide access to education services for all students. At the peak of the crisis, schools were closed in more than 190 countries and approximately 1.5 billion learners were affected (UNESCO, 2020). Countries have quickly responded to this crisis, leveraging print, radio, television, phones and online tools to support learning.

Alternative learning has helped ensure some continuity of education during the pandemic. Unfortunately, as with regular education services, some students have been disadvantaged more than others. While many countries have leveraged pre-existing alternative learning approaches to provide continuing education services, this has been more difficult in low- and middle-income countries (LMICS) where these tools were not as readily available. In particular, marginalised students within these countries (e.g., children with special needs, children from low socio-economic backgrounds, those in remote areas) have been disproportionately disadvantaged by the pandemic.

This brief provides guidance and recommendations on how to support the education of deaf children in Pakistan using alternative learning approaches. It presents the rationale for adopting certain teaching and learning strategies when supporting the learning and well-being of deaf children during global uncertainty. Children with deafness and hearing loss are particularly vulnerable now that schools are closed. They are isolated at home and unable to access information as easily as when they were attending school. This brief presents some of the practices that are reportedly working well for deaf children in different contexts.

While this brief presents an array of options and makes a number of recommendations, it is important to note that not all alternative learning materials and approaches are suitable for all deaf children. Literacy levels and personal learning needs should be assessed by educators and content providers before a specific practice is applied. Educators and caregivers should also monitor children's progress and consult their parents to provide the best learning support.

\subsection{Methods}

The evidence to inform the brief was gathered in three ways:

1. A desk-review incorporating 37 peer-reviewed research studies meeting the inclusion and exclusion criteria out of a total of 1,708 resources (between 1999-2020) from:

- EBSCO (a platform of five important databases in the field of education British Education Index and ERIC Education Databases);

- Psychlnfo (psychological, social, behavioural and health sciences);

- Proquest Social Sciences (social sciences database)

- Web of Science (science, social science and the arts and humanities).

- International organisations and agencies working in SEN with a focus on 'deafness'.

2. A short questionnaire comprising 5 questions was emailed to a large database $(500+)$ of international Deaf organisations, schools for the Deaf, Hearing Resource 
Bases and peripatetic services in England, Wales and Northern Ireland. A total of 10 completed questionnaires from the British Association of Teachers of the Deaf, teachers of the deaf from 4 peripatetic services, 4 hearing resource bases, 1 School for the Deaf in England.

3. Consultation with key partner organisations (NGOs and Disabled Persons Organisations): USAID, British Association of the Deaf, Family Educational Services Foundation.

Although there were only a few responses from the questionnaire, those who did respond were able to share some of the practical low to high tech solutions they have been testing to address the individual learning needs and safeguarding issues of deaf children who are at home. The quotes cited in the sections below have been extracted from the teachers of the deaf responses to the short questionnaire.

\subsection{Background information about deafness}

The WHO estimates 34 million children globally have moderate, severe or profound hearing loss in the better ear. The majority of these (up to 80 per cent) live in low- and middle-income countries (WHO, 2020). Deaf children are a heterogeneous group with a range of needs including:

- level of hearing loss they've experienced

- type of amplification they require

- change in hearing loss they've experienced

- their mode of communication

- the age they were when they received their diagnosis.

Approximately 90 to 95 per cent of deaf children globally are born to hearing parents (Skutnabb-Kangas, 2008). Around 22 per cent of deaf children are recorded as having additional-to-deafness needs, most commonly, severe learning difficulties (CRIDE, 2019). The degree of hearing loss affects the access a person has to sounds. Mild hearing loss can lead to inattention, mild language delay and mild speech problems. Mild hearing loss can have implications around language development, particularly in the early years when children are still developing language. Children with moderate hearing loss do not perceive all speech sounds at a normal conversational level. These children may show inattention, language delay, speech problems and learning problems. They typically respond well to language and educational activities with the help of amplification. In the case of severe hearing loss, language and speech will not develop spontaneously. Without amplification (e.g., hearing aids, cochlear implants), children with severe hearing loss cannot hear sounds or normal conversations. Children with profound hearing loss are likely to have severe language delays, speech problems and possible related learning dysfunction (Northern \& Downs, 2002). 
Hearing loss is measured in decibels (dB). Loss can be mild, moderate, severe or profound and can occur in one or both ears. The degree of hearing loss is categorised as follows

- Mild hearing loss 21-40 dB

- Moderate hearing loss 41-70 dB

- Severe hearing loss 71-95 dB

- Profound hearing loss in excess of $95 \mathrm{~dB}$.

\subsection{Use of terminology}

There are a number of terms used in deaf education to refer to people with hearing loss. However, there is inconsistency in definitions used across professions, countries and deaf people themselves. The term 'hard of hearing' is mostly used to refer to people with mild to severe hearing loss. Medical practitioners use the term 'hearing impaired' for this group. This term is sometimes considered more acceptable than either 'deaf' or 'hard of hearing'. However, the use of the term 'hearing impaired' can be offensive for people as it puts an emphasis on the 'impairment' that a person might face due to his / her disability (medical model of deafness). On the other hand, the term 'deaf' with a small ' $d$ ' can be used to describe people with any level of hearing loss.

\section{Box 2. Deaf terminology}

The term 'Deaf' with a capital ' $D$ ' is used to describe deaf people who are proud of being deaf, are part of the Deaf community and who's preferred communication method is sign language.

The term 'deaf' is used in this report to refer to children with all levels of hearing loss and all types of hearing loss. This ranges from mild to profound, on one or both ears, temporary or permanent hearing loss.

\subsection{Communication of deaf children}

The main types of communication that deaf children use are:

- Sign language as a first language (Sign-Bilingual)

- Listening and speaking (Auditory-Oral or Oral / Aural)

- Using a combination of methods flexibly - (sign, speech and hearing), finger-spelling, gesture, facial expression and

- Lip-reading

Children whose preferred method of communication is oral are mainly educated in mainstream schools. Conversely, children who prefer to communicate using sign 
language usually attend special schools or resource rooms. In England, the majority (around 78 per cent) of school-aged deaf children attend mainstream schools (where there is no specialist provision). Approximately 6 per cent attend mainstream schools with resource provisions, 3 per cent attend special schools for deaf children and 12 per cent attend special schools not specifically for deaf children.

Approximately 90 to 95 per cent of deaf children throughout the world are born to hearing parents (Skutnabb-Kangas, 2008). The variety of language and modes currently in use with deaf children means that parents and other family members must actively decide between the different language and communication approaches to use with a deaf child. If they choose signing, they have to consider whether they want to use signs in conjunction with spoken language (sign supported system), or only use sign language.

The decisions families make will have implications for communication within the family, the support the child will need, and the educational placement that will be appropriate. Children born in families who are part of a Deaf, sign-language-using community are more likely to embrace the Deaf identity (e.g., Martha's Vineyard, USA), to choose to function in a world that celebrates the Deaf culture and to use signing as the main way of communication. As a result, these learners will receive support in using sign language and are most likely to be educated in a setting that celebrates and embraces this identity. In contrast, a child born in a hearing family with a mild-moderate hearing loss, or a child with profound hearing loss who has cochlear implants, might feel more included in the hearing world and embrace a hearing identity. ${ }^{1}$ This child might be educated through spoken language and choose to socialise with peers using spoken language. In addition, deaf individuals might choose to align themselves with both worlds (i.e., Deaf and hearing) and embrace both identities.

Closely linked to the type of communication used by deaf children is the type of amplification. Hearing aids are designed to make sounds louder and focus on sounds that are relevant for understanding speech. Although the human ear can detect sounds between the frequencies of $20 \mathrm{~Hz}$ and $20 \mathrm{kHz}$, speech sounds fall largely between $150 \mathrm{~Hz}$ and $8 \mathrm{kHz}$. Hearing aids are therefore focused on amplifying these frequencies, though they are limited in their response to high-frequency sounds. There are different types of hearing aids for different degrees of hearing loss and depending on the needs of different children.

\subsection{Impact of deafness on language and learning}

Hearing children enter school with knowledge about the forms and functions of written language (i.e., print knowledge). It is essential to consider here the prerequisites to develop the ability to read and write. The link between language skills and literacy development is well established for hearing children. However, deaf children might have limited print knowledge when they enter school as they lack the auditory input. This knowledge is acquired in a variety of ways including incidental learning and

\footnotetext{
${ }^{1}$ A cochlear implant is a surgically implanted electronic device that provides a sense of sound to a person who has a severe or profound hearing loss. A cochlear implant does not cure deafness or hearing impairment but is a prosthetic substitute which directly stimulates the cochlea.
} 
interaction with adults ${ }^{2}$. Digital hearing aids received earlier in a child's life due to early identification of deafness are likely to have a positive impact on the language and literacy skills of a deaf child. Whilst some studies in the US have demonstrated that children who receive implants early in their lives can achieve age-appropriate reading skills (Geers, 2003), studies in the UK have shown less positive results with some deaf children not achieving age-appropriate reading levels (Harris, Terlektsi, \& Kyle, 2017).

\subsection{Deaf students and distance learning}

Literacy is an important skill to enable individuals to feel included in society. A lack of literacy can give rise to feelings of exclusion. Literacy is of even greater importance to deaf pupils. The increasing availability of closed-caption television programmes demands that deaf pupils are able to read subtitles, while modern communication systems (e.g., e-mail, Facebook, text messaging) can be extremely beneficial to deaf pupils, particularly those for whom using a voice telephone is difficult or impossible.

Distance learning can be a challenge for deaf students because of the literacy difficulties they encounter. Deaf children face difficulties in reading comprehension. When designing distance-learning courses, text should be kept to a minimum since deaf children may present difficulties in reading comprehension. When designing e-learning systems for deaf and hearing-impaired individuals, it is essential to provide all audio in a visual way using text, subtitles, pictures and signed videos and also to create a graphical interface that effectively presents educational activities in a logical and effective way (Pappas et al., 2018).

\footnotetext{
${ }^{2}$ Incidental learning refers to any learning that is unplanned or unintended. It develops while engaging in a task or activity and may also arise as a by-product of planned learning.
} 


\section{Pakistan context}

\subsection{Child deafness in Pakistan}

While a lack of data on the prevalence and causes of functional impairments in children in LMICs, including deaf children, is a major barrier to providing appropriate health services to meet their needs, some limited data exists (WHO, 2011). An estimated 93 million children globally are in need of services related to their disabilities (Bornstein et al., 2013). Approximately 1.2 out of every 1,000 Pakistani children that are screened are impacted by moderate to profound, congenital, bilateral hearing loss (i.e., hearing loss occurring in both ears) (Mactaggart et al., 2013). In comparison, in the UK, the prevalence is slightly lower with 1.0 out of every 1,000 births (Uus \& Bamford, 2006), while in India it is approximately 5.6 children per 1,000 live births (Mandke \& Chandekar, 2019). However, these figures are based on official government statistics whilst figures for Pakistan are not officially confirmed.

There are two languages of the Deaf Community in Pakistan: Indo-Pakistani Sign Language (IPSL) ${ }^{3}$ and Pakistan Sign Language (PSL). ${ }^{4}$ Similar to spoken languages, both IPSL and PSL have a variety of dialects in different regions of the country. While many common words are shared, some will be region-specific.

\subsection{National government policy on special education in Pakistan}

The Pakistani Government has recently introduced a policy which addresses the rights, and the social and learning needs of persons with disabilities. Pakistan's recent 'ICT Rights of Persons with Disabilities Act, 2020' is closely aligned with Article 24 of the UN Convention on the Rights of Persons with Disabilities, which affirms that States should provide 'reasonable accommodation' to ensure that persons with disabilities 'enjoy or exercise on an equal basis with others' and 'have equal access to quality devices, assistive technologies, and forms of assistance' (Government of Pakistan, 2020; United Nations, 2007, p. 2). The Council also pledges to enforce guidelines allowing persons with disabilities to have full and appropriate access to all forms of communication and technology. Clause 9 - Equity in Education (no. 4) - pledges to 'reasonably' equip special educational establishments and appropriate facilities for 'inclusive education'.

The Digital Pakistan Policy Strategy (2018) is closely aligned to the UN Sustainable Development Goals (e.g., Goal 4: Quality Education). It sets a bold vision to encourage 'mass adoption of emerging digital technologies and innovative applications to enable cross-sector socio-economic development and transformation of economic activities, governance models, social interaction, and achievement of sustainable development goals'. In terms of increasing ICT access to persons with disabilities, the Government of Pakistan in Section 7 (p. 12) sets out specific goals:

\footnotetext{
${ }^{3}$ For more information on IPSL see Chapter Chapter 12 "Regional variation in Indo-Pakistani Sign Language - Evidence from content questions and negatives" (Ulrike Zeshan, 2006). This chapter is available at: https://library.oapen.org/bitstream/id/1411bda8-98d1-4fce-bbe2-9d7180320c21/453832.pdf

${ }^{4}$ For more information on PSL see PSL (n.d.). This information is available at: http://www.psl.org.pk/about/about-psl
} 
1. Involve Civil Society, Private Sector Organisations and other relevant stakeholders for developing and instituting a holistic ecosystem to promote ICT accessibility for Persons with Disabilities.

2. Collaborate with local and international software industry to introduce ICT infrastructure and software applications for PWDs along with local language support.

3. Ensure compliance of universal standards in development of websites that allow inclusiveness of the PWD community.

4. Encourage the local development of software tools for persons with disabilities and its availability at economical rates.

(Source: The Digital Pakistan Policy, 2018)

All four of the above objectives in the Digital Pakistan Policy Strategy are particularly relevant to the learning and well-being of deaf children in Pakistan. However, considering the current pandemic, it is more important that government education authorities and private service providers collaborate closely with the international software industry to find ways to procure essential ICT equipment and hardware, and seek ways to freely share learning material in accessible formats to deaf learners.

\subsection{School provision for deaf children}

Evidence of information on deaf education in Pakistan is scarce. Deaf education in one of the four administrative provinces of Pakistan (Khyber Pakhtunkhwa) is delivered through hearing aids, audio-system voice therapy, speech-therapy training, sign language, finger-spelling, lip-reading and total communication. In general, schools for deaf children in Pakistan lack resources and classrooms can be poorly organised and overcrowded (Mushtaq \& Reba, 2017). Again, in general, deaf children are mainly educated in state segregated educational schools, although a small proportion are educated in private schools for the deaf (e.g., the Family Educational Services Foundation; FESF). ${ }^{5}$ However, as a result of global policy moves towards inclusive education as mentioned above, Pakistan is taking steps towards a more inclusive education for deaf children.

\subsection{Distance learning for deaf children in Pakistan}

Online resources can provide a range of online learning options. For example, Pakistan Sign Language offers an extensive range of invaluable online learning resources for deaf students and their families. Based on an informal survey of 1,200 deaf children attending private special schools carried out by FESF, only 20 per cent of deaf families have access to the internet, therefore resulting in 80 per cent not being able to access digital online resources. In order to mitigate this lack of internet and make these resources available to a larger number of deaf students, FESF has developed a purpose-built platform that supports access by those who have little or no access to the internet or devices. Funded through DFID Pakistan, FESF is also working with its school

\footnotetext{
${ }^{5}$ For more information on FESF see FESF (n.d.). This information is available at: https://www.fesf.org.pk/
} 
teachers to provide signed video lessons in its studio, deliver laptops and USBs with new content using its pool of mini-buses and collaborating with internal and external connections with partners to provide games and reading materials and psycho-social support to all of 1,200 deaf children. (See Box 2).

Box 2. The Family Educational Services Foundation's (FESF) response to rising demand for online learning for deaf children in Pakistan (Source: Consultation with FESF)

1. Procure laptops and upload learning content (PSL alphabet, visual stories, recorded signed class lessons) for 1,200 children.

2. Set up a lending agreement for the loaning of laptops between the school and the child's family.

3. Use the school transport system and school teachers to distribute supplementary worksheets once / twice a month on a USB downloaded onto the borrowed laptop. Save completed worksheets for marking by teachers. Teachers check in with the child and family during these visits (observing social distance regulations).

4. Child's teacher keeps in touch with the child's family using Whatsapp, SMS or calling the family.

FESF is currently negotiating additional resources to support their children's well-being including:

1. Partnering with a mental health organisation that supports children's medical and mental health (e.g., dealing with issues of anxiety and social isolation).

2. Gamifying new learning content and addressing anxiety and social isolation by partnering with deafkidz International. ${ }^{6}$ Deafkidz has experience in responding to issues related to the protection, health and well-being of deaf and hard-of-hearing children.

\footnotetext{
${ }^{6}$ For more information on deafkidz International see deafkidz International (n.d.). This information is available at: https://www.deafkidzinternational.org/
} 


\section{Discussion of distance-learning solutions for deaf children}

\subsection{Hardware and equipment for distance learning}

The desk-based review conducted for this brief did not provide information or evidence on the type of hardware and equipment that can be used to support deaf children's distance learning (REA). However, the interview with the Family Educational Services Foundation (FESF) and questionnaires completed by practitioners provided valuable data. All quotes included below are taken verbatim from these interviews and questionnaires.

The hardware needed to deliver distance learning ranges from laptops, phones, web-cameras, and headphones to TVs. Access to appropriate technology was identified as pertinent by ten practitioners replying to the questionnaire. Six out of ten teaching practitioners emphasised the importance of maintaining the hardware and ensuring that families have access to the right equipment. In most cases schools have a dedicated technician who can work with the family to solve technical problems. As one teacher commented:

"The quality of the hardware and software are absolutely central. Once glitches are resolved, learning can happen." (Director of FESF)

In cases where families do not have access to laptops, phones and other devices, the schools can loan equipment to the families. Providing hardware to families is also central to the work of FESF:

"Less than 20 per cent have access to the Internet, poor families. FESF provides low cost devices - low cost (\$200) refurbished laptop or tablet." (Director of FESF)

For children using PSL, FESF can transfer the content of the PSL website onto USBs to use on the refurbished laptops.

The importance of ensuring that deaf children have appropriate equipment to access the spoken language of recorded materials and synchronous teaching was also mentioned by the practitioners. It is important that children use the right equipment at home to maximise their residual hearing and the input they get from their amplification. For children using hearing aids, the Roger Pen, a wireless microphone used in combination with hearing aids, can be plugged into the headphone socket. ${ }^{7}$ In addition, children using cochlear implants can stream audio through a mini microphone paired with the cochlear implant. ${ }^{8}$ This ensures they can hear the audio of the videos and real-time voice better, cutting out the sounds they don't want to hear.

\footnotetext{
${ }^{7}$ For more information on the Roger Pen see Phonak (n.d.). This information is available at: https://www.phonak.com/uk/en/hearing-aids/accessories/roger-pen.html

${ }^{8}$ For more information on Cochlear Implants see Ture Wireless Accessories (2015). This information is available at:

https://www.sacic.com.au/assets/cochlear-downloads/True-Wireless-Accessories-User-Guide.pdf
} 


\subsection{Software for distance learning}

The practitioners' questionnaires also provided insights into the platforms, applications and web services used by practitioners to deliver distance learning to deaf children.

Nine out of ten practitioners are currently using virtual classrooms to deliver online teaching. The main tool used by teachers in order to develop online classrooms is Google classroom. ${ }^{9}$ Google classroom is a free web service that allows teachers and students to share materials and make announcements. Most importantly it also allows students to interact with the materials and each other. They have the ability to comment on assignments and announcements, as well as to email each other using the classroom interface. This service is commonly used by schools to deliver distance learning as it is easy and free to use. As one teacher commented on the questionnaire:

"Google Classroom allows you to record lessons, present lessons during a Google hangout meeting. We use our school computer, chrome books with webcams and headphones/mics to ensure clarity of the voice is picked up. "(Peripatetic service in England)

Other popular free access platforms are Purple Mash and Seesaw. ${ }^{10}$ Purple Mash provides free learning content for multiple subjects delivered in a fun and engaging way. It also provides a platform for remote learning. Some teachers also use other tools for synchronous teaching which allow students to interact with their peers. This includes Zoom, WhatsApp and Facebook classrooms.

In relation to the use of synchronous learning and online tools, two practitioners commented on the importance of safeguarding children and on the school's decision to not use online platforms:

"We decided against virtual classrooms, due to the safeguarding regulations and the difficulties with hearing and lip-reading deaf students face. In addition, we also decided not to go forward with synchronous teaching due to the different ability levels and also the difficulty in able to follow information, with lots of other students being involved. Alternatively, we are communicating with our students via a system called Firefly. All students have an account, as well as staff. We can set tasks for either groups of students or individuals. They are able to carry out the task, communicate with members of staff and we are notified once the work has completed. They can also ask for assistance, which we send in the form of scaffolding worksheets. We also rely on e-mails and make two phones calls a week to identify any issues in regards to learning and wellbeing." (Teacher of the Deaf, England)

"For us as a Junior School, we have followed union advice and not offered live video lessons. We use pre-recorded films for our sign language users for stories, messages, instructions for activities etc., which we either post on the website or share via Dojo.

\footnotetext{
${ }^{9}$ For more information on Google Classroom see Google Classroom (n.d.). This information is available at: https://edu.google.com/products/classroom/?modal active=none\#\%2Fready-to-go ${ }^{10}$ For more information on Purple Mash see Purple Mash (n.d.). This information is available at: https://2simple.com/purple-mash/. For more information on Seesaw see Seesaw (n.d.). This information is available at: https://web.seesaw.me
} 
Therefore, teaching is asynchronous but feedback is always given when children post work or photos." (Teacher of the Deaf, England)

\subsection{Delivery mediums for distance learning}

The first decision in distance learning is whether the delivery is taking place in real time (synchronous) or in a distant time (asynchronous). In synchronous distance learning the learner needs to be available at the same time as when the teaching takes place. A specified time needs to be arranged for participation. In asynchronous teaching the learner can engage in conversations at their own speed. When the teaching material is available the learner can drop in and engage with the materials at any time. The ability to take time and reflect on content and discussions means asynchronous learning can lead to better academic results for deaf students compared to campus-based courses (Long, Marchetti \& Fasse, 2011). Deaf students following online courses are able to communicate with the instructor and as a result levels of satisfaction tend to be higher.

It is clear that teaching to deaf children has to be delivered in a visual and engaging way. This is particularly important when children communicate via sign language and their access to sound is limited. This means the use of visual presentation is paramount, as one teacher of the Deaf points out:

"Use visual images / step-by-step powerpoint. Don't have too much info on the slides, keep it simple." (Teacher of the Deaf, England)

The issue of teaching sign language to deaf children has been addressed by the use of a signing avatar (Zirzow, 2015). A signing avatar is a virtual-reality character that can communicate using sign language. These can be used in order to teach deaf children how to use sign language for communication but also academic concepts especially in maths and science. There are a number of different applications using signing avatars. There is no evaluation of the use of this virtual-reality tool regarding its effectiveness on children's learning outcomes.

Virtual-reality games are useful to teach mathematical concepts using sign language (Alhadeff, 2007). These games can provide students with a walkthrough with different settings to select, grasp, move and release objects, and communicate in sign language.

\subsection{Accessibility of distance learning}

Given the heterogeneity of deaf children (i.e., type of communication used, access to sound, type of amplification, age of diagnosis, type of educational setting etc.), it is important to emphasise that materials produced must be designed to meet the needs of individual children. The National Deaf Children's Society (NDCS) provides guidelines on how to deliver inclusive education for deaf children online. ${ }^{11}$ The guidelines emphasise the need to avoid assumptions that all deaf children can benefit from the same distance-education provision:

\footnotetext{
${ }^{11}$ For more information about the National Deaf Children's Society see National Deaf Children's Society (n.d.). This information is available at:

https://www.ndcs.org.uk/blog/how-to-provide-inclusive-online-learning-for-deaf-children/
} 
"A top tip is to avoid a generalised package of 'deaf support' and instead use a learner-centred approach that makes the most of the young person's strengths. Many deaf learners use a mix of hearing, technology, BSL, lip-reading, and text support, meaning that there is not a set package of things that make online learning accessible to deaf people."

The World Federation for the Deaf stresses the importance of making online materials and resources accessible to deaf learners. ${ }^{12}$ One example of the WFD's work in this area is in strengthening the WHO Disability Guidelines on suitable technology for deaf in LMICs (World Health Organization, 2019). Whereas it previously said sign language interpretation should be provided 'if possible' this has now been changed to mandating national sign language interpreters. More recent evidence suggests that the most important factor in accessibility of teaching materials is the subtitling of videos (Lago \& Acedo, 2017). This is followed by the availability of instructors proficient in sign language, the translation of texts into sign language and the availability of texts at different levels of reading difficulty.

Using YouTube videos to elaborate specific points or demonstrate teaching in a visual way is a common practice in distance education. However, in order for videos to be accessible, the use of captions is pertinent. The accuracy of translation is one criteria to determine whether communication is effective for people who need captions, specifically for individuals who are deaf. Auto-generated captions or manual captioning can be used. When video-captioning takes place manually this can be time consuming. Although YouTube's auto-captioning is less accurate, it is an easy solution that reduces time spent on manually creating captions. In most situations, auto-generated captions might not 'meet the needs' of deaf students in terms of providing accurate subtitles (Parton, 2016). Balancing the need for accuracy against the need to get materials to students in a timely manner is a decision that must be made on a case-by-case basis.

It is important to ensure learning is accessible to all deaf children and that all language used in online content can be digested with minimal effort. This is particularly important for those children who have limited vocabularies. Written language, therefore, has to be intelligible - the message has to be clear, relevant, coherent, cohesive and usable, in that it is effective and appropriate for conveying the message (McKeown \& McKeown, 2019). Actively using mental imagery to support new vocabulary acquisition is also seen (Howell, 2003) to be effective.

There is evidence that the effectiveness of captions is strongly related to the reading level and vocabulary skills of deaf learners. Deaf children who have smaller vocabularies and lower reading abilities demonstrate more difficulties in understanding captions and understanding online materials (Lewis, 2001). Also, learners who use online materials with both signed videos and captions demonstrate better content comprehension and less cognitive overload compared to those who watch materials only supported by signed videos (Yoon \& Kim, 2011).

We should also consider how socio-cultural norms might dictate access to technology for deaf and other children with disabilities. Girls may have less access to technology

\footnotetext{
${ }^{12}$ For more information about the World Federation for the Deaf see World Federation for the Deaf (n.d.). This information is available at: https://wfdeaf.org/
} 
like mobile phones than boys. Teachers may not have access to technology at home and will also require support. Similarly, while in theory some technologies might facilitate distance-learning opportunities for deaf children, socio-cultural norms might keep them disconnected. These norms can further exacerbate disparities and separate learners from opportunities to learn.

Educators of deaf students should be cognisant of how factors such as reading ability, language cognition and the need for visual reinforcement of learning content can impact a student's desire to access content (Lang \& Steely, 2003). It is not just a matter of making sure all visuals are captioned or signed but also about modifying the language:

"We ensure that we modify the oral language of the mainstream classroom work and Create deaf-friendly worksheet-booklets" (Peripatetic service, England).

Another accessibility related aspect that needs to be taken into consideration is the duration of online sessions and their interactive and fun nature. The following accessibility features were identified by the teachers' questionnaires:

"Keep sessions short and interactive - e.g, go and find something starting with a letter."

"Use visual aids."

"Reduce screen and listening fatigue."

"Use colourful, clear and engaging websites, images at the right level."

(Two Teachers of the Deaf, England)

Deaf students in higher education identified the following features as the most important for effective distance learning (Pappas et al., 2018):

- special graphic utilisation and existence of examples as well as explanatory videos

- description of definitions and terms

- revision after each module

- use of videos in sign language

- short duration of modules.

To summarise, the variability of the population of deaf children and their individual needs have to be taken into account when delivering distance learning. The use of subtitles, sign language interpreters but also the use of language that has a clear meaning, is relevant and cohesive is really important. Keeping sessions short, interactive using visual aids is of great importance for the accessibility of the materials and for the engagement of the children

\subsection{Monitoring and evaluating distance learning for deaf children}

This research did not identify any studies providing evidence on the effectiveness of distance learning on learning outcomes of deaf children. However, the importance of monitoring and evaluating students' progress and learning was emphasised in the practitioners' questionnaire and in the interview with FESF. The most important factor contributing to the effectiveness of an online learning programme is parental collaboration. The key to successful remote working relies on the relationship staff have 
established with parents. Where parents had a positive view of the schools' support, it has been much easier to support the students. The different ways used to involve parents, especially those with no or limited access to technology was documented by the teachers:

"We get two or three preschool families in a group call to do singing / read a story children and families can see each other."

"We have communicated via email / text / phone call / video call."

"We use Telephone calls and text messages, posting (and in some cases, doorstep delivery) of resources."

(Peripatetic Service, England)

"In everyday school life, we use an app, Dojo, to communicate with parents. The app enables us to message parents individually as well as a group. There is also a class page we use for adding photos of group activities undertaken etc., and then each pupil has an individual profile page. Throughout Lockdown, the app has proved an invaluable tool for maintaining contact with our families. In those early days, it was used daily to message parents, check in, alert them to any work and direct them to any website links which may be of interest (there was so much in those early days). Daily language based activities were suggested, utilising the rainbow writing and other resources in the pack."

(Resource Base, England)

Communication with families serves two aims outlined by the schools:

1. Teachers ensure that parents are supported during distance learning.

2. Parents provide information on children's progress and engagement with the materials.

"Phone calls have been the most successful and easiest way and possibly for parents, they need the reassurance, ideas and emotional support that is incidental. Also, encourage families / parents to provide an email address if possible for those who have access to technology as this becomes an easier way to communicate on a long term basis."

It is evident from teachers' questionnaires that parents need support and guidance to help deaf children with distance education. As one teacher replied to the questionnaire:

"Parents have appreciated a phone call, often to ask how to deliver work set by school which suggests not enough guidance / examples given to parents. As many parents have said to me 'I'm not a teacher I don't know how to teach this.' Phone calls for those parents who may need extra support. Email some suggestions, ideas for support to larger number of parents with tips, suggested websites for which curriculum area I age-range etc." (Teacher of the Deaf, England)

As distance learning is taking place at home, schools are gradually finding effective ways to support families with setting learning expectations and finding ways to achieve learning outcomes. One way to gain insight into how children engage with the materials and how effective they have been is to have regular contact with parents:

"We offer continuous provision of help and support in e-mail from 8:30 to $3 \mathrm{pm}$ to parents every day." (Peripatetic Service, England) 
What is missing from the literature and the practice in schools regarding distance learning is an effective and consistent way to evaluate the learning outcomes for deaf children. Schools have taken some steps in this direction:

"Children can take pictures of certain tasks that they need help with at any time and send it to the teacher of the deaf by email. A teacher of the deaf breaks it down or modifies language instantly and sends it back to [the] student." (Teacher of the Deaf, England)

However, evaluation has to be developed to measure:

- the appropriateness of the materials

- whether they meet the objectives

- how the resources are used

- the difference that the materials are making to students' progress and learning

- the sustainability of the knowledge.

It is critical for donors and Ministries of Education to collect data on children's ability to access and use technology as well as collecting data on their learning outcomes. This data needs to be disaggregated as much as possible, to capture information such as gender, location and level of hearing loss as part of monitoring and evaluation procedures. For example, consider how accessing information via remote means affects the quality, accessibility and relevance of the data. It may be feasible to ask teachers to collect some of the data when they contact their students via phone or visit their homes. In addition, data protection and safeguarding of deaf children and their families (i.e., a vulnerable group) is of major importance and should be taken into account when engaging in virtual teaching using online platforms.

\subsection{Examples of international projects responding to Covid-19 for deaf children}

READ II: Under the READ II activity, Ethiopia has quickly pivoted to provide educational content to children affected by the COVID-19 pandemic through radio and TV. The Ethiopian Broadcasting Corporation (EBC) and regional stations have started broadcasting the children's education programme 'Tsehai Loves Learning' on TV and radio. The national and regional weekly broadcasts are expected to reach millions of children, helping them practise reading and literacy skills from home during the COVID-19 pandemic. The TV programming includes sign language so that deaf children benefit too.

eKitabu: The Kenyan Ministry of Education has set up an agreement with eKitabu to provide signed digital stories for deaf children in Kenya and Rwanda. Nairobi-based eKitabu has been featuring a half-hour Digital Story Time across Kenyan TV, YouTube and ekitabu.com. Each episode features Kenyan Sign Language (KSL) and Rwandan Sign Language (RSL) videos and story books designed to help all children continue their learning while schools are closed.

Inter-agency Network for Education in Emergencies (INEE): The INEE has developed a response to help donors and Ministries of Education prioritise their actions during the 
crisis. The tool provides minimum standards to ensure well-being. These include procuring materials needed for at-home learning kits before supply chains shut down, prioritising health and hygiene education, protecting wellbeing, coordinating work, analysing the context, developing an activity plan and reviewing progress and quality.

Humanity and Inclusion: Humanity and Inclusion has published a series of guidance notes to support schools during the Covid-19 crisis. ${ }^{13}$ The guidance notes include \#1Inclusive Digital learning \#2 - Teacher resources and \#3 Home support. It provides links to resources for children with disabilities, including deaf children. These include:

- The global Digital Library provides digital storybooks and other reading materials easily accessible from mobile phones or computers. This resource is very easy to use, and there are thousands of titles available in 43 languages, and the materials can be used offline.

- Storyweaver is great for multilingual stories, although it's less extensive. It is useful for encouraging children to read local context books and stories. This also includes some audio-visual story books for children with visual impairment (readalong).

- Deaf World Around You is a useful platform for young children with hearing loss, with accompanying videos in sign language, to go with each story.

\footnotetext{
${ }^{13}$ For more information on Humanity and Inclusion's guidelines for Inclusive Digital Learning during COVID-19 see Humanity and Inclusion (2020). This information is available at: https://www.hi-us.org/inclusive digital learning covid19 brief
} 


\section{Recommendations}

Based on the findings and practices outlined in the previous section, a number of key recommendations are presented below. These recommendations highlight the main steps that should be taken by education-sector actors to ensure deaf students are provided with the best possible distance learning experience.

The recommendations are divided into two student segments - students who have no or limited access to hardware / software / internet and those who have some access. This approach aligns with Haßler, Khalayleh \& McBurnie's (2020) recommendation to strategically target COVID-19 responses to specific population segments based on their access to different modalities (e.g. TV, online, etc.).

The recommendations also consider the different methods of communication and amplification that students use and attempts to provide a timeline of when the recommendations can be implemented, i.e., immediate (one to 3 months), short term (one to six months), medium term (six months to one year), and long term (one to two years).

Table 1. Recommendations for delivering distance education to families with no or limited access to hardware, software and the internet in the immediate to short term.

\begin{tabular}{|c|c|c|c|}
\hline Thematic area & Recommendations & $\begin{array}{l}\text { Examples of how to } \\
\text { implement the } \\
\text { recommendations }\end{array}$ & Timeline \\
\hline $\begin{array}{l}\text { 1. Content } \\
\text { development }\end{array}$ & $\begin{array}{l}\text { Content developers } \\
\text { should ensure that the } \\
\text { background of the } \\
\text { videos are clear and that } \\
\text { the speaker is facing the } \\
\text { camera }\end{array}$ & $\begin{array}{l}\text { Keep clear backgrounds, avoid } \\
\text { extraneous noise. } \\
\text { For easier access to lip patterns, } \\
\text { teacher has to be at the front of } \\
\text { the class, facing the camera, } \\
\text { standing still (i.e., not moving } \\
\text { around the classroom), with } \\
\text { good lighting, and displaying } \\
\text { their hands clearly. }\end{array}$ & Immediate \\
\hline $\begin{array}{l}\text { 2. Cognitive } \\
\text { load }\end{array}$ & $\begin{array}{l}\text { Content designers } \\
\text { should ensure online } \\
\text { modules / activities are } \\
\text { short to avoid cognitive } \\
\text { overload and fatigue. } \\
\\
\text { Teachers should ensure } \\
\text { students are allocated } \\
\text { an appropriate amount } \\
\text { of material to engage } \\
\text { with while away from } \\
\text { school - not too much } \\
\text { to overload or not } \\
\text { enough. }\end{array}$ & $\begin{array}{l}\text { Ensure that work is sent } \\
\text { steadily so that students don't } \\
\text { feel overwhelmed. } \\
\text { The slots should be short - } \\
30-40 \text { minutes maximum. } \\
\text { Set a timer on the device to } \\
\text { remind children of when to } \\
\text { stop. }\end{array}$ & Immediate \\
\hline
\end{tabular}




\begin{tabular}{|c|c|c|c|}
\hline $\begin{array}{l}\text { 3. Material } \\
\text { provision }\end{array}$ & $\begin{array}{l}\text { Schools provide hard } \\
\text { copies of tasks / } \\
\text { activities / sign-language } \\
\text { booklets including visual } \\
\text { images and are easy to } \\
\text { follow. } \\
\text { Schools should provide } \\
\text { hard copies of how to } \\
\text { care and maintain } \\
\text { equipment (e.g., } \\
\text { maintenance of assisted } \\
\text { listening devices etc.) to } \\
\text { students and families. }\end{array}$ & $\begin{array}{l}\text { Teachers of the deaf sign video } \\
\text { short lessons ( } 20 \text { mins), transfer } \\
\text { to external hard-drive or USBs } \\
\text { and prepare activity worksheets } \\
\text { for } 2-3 \text { weeks home-schooling. } \\
\text { Schools transport packs of work } \\
\text { to the home in print or on a } \\
\text { USB (or external hard drive) to } \\
\text { be uploaded to a child's laptop } \\
\text { or device. } \\
\text { Completed tasks (e.g., } \\
\text { worksheets) are sent back to } \\
\text { the teachers for marking and } \\
\text { feedback either via phone or by } \\
\text { sending back the activities with } \\
\text { comments the following month. }\end{array}$ & Immediate \\
\hline \multirow[t]{2}{*}{$\begin{array}{l}\text { 4. Language, } \\
\text { captioning }\end{array}$} & $\begin{array}{l}\text { Teachers should use } \\
\text { plain, intelligible and } \\
\text { usable language to } \\
\text { address the literacy } \\
\text { difficulties of deaf } \\
\text { children. }\end{array}$ & $\begin{array}{l}\text { Language used in distance } \\
\text { teaching of deaf students } \\
\text { should be simplified to the } \\
\text { understanding of deaf students. } \\
\text { Use of mental imagery to } \\
\text { support vocabulary acquisition } \\
\text { of deaf children can be } \\
\text { effective. e.g. cartoons, images } \\
\text { and subtitles. }\end{array}$ & Immediate \\
\hline & $\begin{array}{l}\text { Content designers } \\
\text { should incorporate } \\
\text { captioning in } \\
\text { combination with } \\
\text { embedded videos of } \\
\text { sign language } \\
\text { interpreters to enhance } \\
\text { accessibility to } \\
\text { materials. }\end{array}$ & $\begin{array}{l}\text { Provide all audio in a visual way } \\
\text { using text, subtitles, pictures, } \\
\text { and sign language videos. }\end{array}$ & Short term \\
\hline $\begin{array}{l}\text { 5. Testing } \\
\text { different } \\
\text { digital } \\
\text { solutions }\end{array}$ & $\begin{array}{l}\text { The Government should } \\
\text { encourage schools to } \\
\text { test out different digital } \\
\text { learning solutions to } \\
\text { help them understand } \\
\text { how technology can be } \\
\text { used to foster deeper } \\
\text { student learning. }\end{array}$ & $\begin{array}{l}\text { School heads provide checklists } \\
\text { for teachers to complete when } \\
\text { visiting children's homes. Note } \\
\text { what works well and what } \\
\text { doesn't work well in relation to } \\
\text { new learning, accessibility or if } \\
\text { students struggling to use the } \\
\text { technology need quick } \\
\text { sign-language demonstrations. }\end{array}$ & $\begin{array}{l}\text { Short- } \\
\text { medium term }\end{array}$ \\
\hline $\begin{array}{l}\text { 6. Evaluating } \\
\text { distance } \\
\text { learning }\end{array}$ & $\begin{array}{l}\text { The Government should } \\
\text { evaluate distance } \\
\text { learning implementation }\end{array}$ & $\begin{array}{l}\text { Continuous provision of help } \\
\text { and support in e-mail from 8:30 } \\
\text { to } 3 \text { pm daily. } \\
\text { Adding parents to google } \\
\text { classroom. Continuously } \\
\text { update and copy parents into }\end{array}$ & Short term \\
\hline
\end{tabular}




\begin{tabular}{|l|l|l|}
\hline & $\begin{array}{l}\text { emails of support (language } \\
\text { modification, visuals, key } \\
\text { words). }\end{array}$ \\
& $\begin{array}{l}\text { https://www.oecd.org/dac/evalu } \\
\text { ation/daccriteriaforeeevelopme } \\
\underline{\text { ntassistance.htm }}\end{array}$ & \\
\hline
\end{tabular}

Table 2. Recommendations for delivering distance education to families with no or limited access to hardware, software and the internet in the medium to long term.

\begin{tabular}{|c|c|c|c|}
\hline Thematic area & Recommendations & $\begin{array}{l}\text { Examples of how to } \\
\text { implement the } \\
\text { recommendations }\end{array}$ & Timeline \\
\hline 1. Partnerships & $\begin{array}{l}\text { The Government should } \\
\text { partner with alternative } \\
\text { education providers } \\
\text { who have already } \\
\text { developed educational } \\
\text { platforms. This might } \\
\text { include NGOs, CSOs, } \\
\text { and private companies. }\end{array}$ & $\begin{array}{l}\text { Ensure adequate online content } \\
\text { for deaf children on TV, free } \\
\text { online learning repositories or } \\
\text { through more mainstream } \\
\text { learning platforms (Facebook, } \\
\text { Google Classrooms). } \\
\text { Consider accessibility issues, } \\
\text { cultural appropriateness and } \\
\text { gender stereotyping when } \\
\text { reviewing suitable materials. } \\
\text { Request content providers if } \\
\text { learning materials can be } \\
\text { modified to contain captions } \\
\text { and signing in PSL. } \\
\text { Some organisations of the deaf } \\
\text { have already made their } \\
\text { resources and services freely } \\
\text { available to some schools to } \\
\text { expand countries. }\end{array}$ & $\begin{array}{l}\text { Medium to } \\
\text { long term }\end{array}$ \\
\hline $\begin{array}{l}\text { 2. Hardware } \\
\text { and equipment }\end{array}$ & $\begin{array}{l}\text { Schools ensure } \\
\text { hardware and } \\
\text { equipment lent to } \\
\text { families are appropriate } \\
\text { for the audiological } \\
\text { characteristics and } \\
\text { communication needs } \\
\text { of the child. }\end{array}$ & $\begin{array}{l}\text { Teachers test and provide at } \\
\text { least one hardware device } \\
\text { (smart phone, tablet) for } \\
\text { children to access signed } \\
\text { learning materials from their } \\
\text { schools or agreed content } \\
\text { provider. } \\
\text { Based on a child's individual } \\
\text { needs - provide microphones } \\
\text { for access to sound or } \\
\text { streaming from Mini Mic and } \\
\text { Roger pen which goes into the } \\
\text { headphone socket. }\end{array}$ & $\begin{array}{l}\text { Medium-long } \\
\text { term }\end{array}$ \\
\hline
\end{tabular}




\begin{tabular}{|c|c|c|c|}
\hline $\begin{array}{l}\text { 3. Device } \\
\text { provision }\end{array}$ & $\begin{array}{l}\text { The federal Ministry of } \\
\text { Education should work } \\
\text { with relevant actors } \\
\text { within both federal and } \\
\text { provincial governments } \\
\text { to create agreements } \\
\text { with hardware suppliers } \\
\text { to procure cheap } \\
\text { laptops or tablets to } \\
\text { children with disabilities } \\
\text { with an agreement to } \\
\text { return them when } \\
\text { schools reopen }\end{array}$ & $\begin{array}{l}\text { Set up new agreements with } \\
\text { existing school suppliers to } \\
\text { provide low-cost devices (e.g., } \\
\text { one laptop-one child scheme), } \\
\text { with at least } 2 \text { USB ports for } \\
\text { additional plug-in devices } \\
\text { (headsets, speakers, etc). } \\
\text { Set up a toll free hot-line for } \\
\text { families to call if experiencing } \\
\text { technical problems. }\end{array}$ & $\begin{array}{l}\text { Short- } \\
\text { medium term }\end{array}$ \\
\hline 4. Accessibility & $\begin{array}{l}\text { Content designers } \\
\text { should ensure materials } \\
\text { follow accessibility } \\
\text { guidelines (i.e., WCAG } \\
\text { W3C Guidelines). }\end{array}$ & $\begin{array}{l}\text { The developed materials should } \\
\text { be child friendly, age } \\
\text { appropriate, non-gender biased }\end{array}$ & $\begin{array}{l}\text { Short- } \\
\text { medium term }\end{array}$ \\
\hline
\end{tabular}




\section{Resources}

\subsection{Organisations providing information about deaf education}

- https://www.ndcs.org.uk/

- https://www.batod.org.uk/

- https://www.ndcs.org.uk/deaf-child-worldwide/

- https://www.deafkidzinternational.org/

- https://wfdeaf.org/

- https://www.sound-seekers.org.uk/

- $\quad$ https://www.globalpartnership.org/blog/help-deaf-children-go-school-help-their-parents

\subsection{Guidance on accessibility of distance learning resources}

- $\quad$ https://www.ndcs.org.uk/blog/how-to-provide-inclusive-online-learning-for-deaf-children/

\subsection{Accessible information for children for COVID -19}

- https://nursedottybooks.com/dave-the-dog-is-worried-about-coronavirus-2/

- https://nosycrow.com/blog/released-today-free-information-book-explaining-coronavirus -children-illustrated-gruffalo-illustrator-axel-scheffler/

- https://www.sesamestreet.org/caring

\subsection{Helpful guidance notes on inclusive digital learning}

- $\quad$ https://www.hi-us.org/inclusive digital learning covid19 brief

\subsection{Online resources / stories for deaf children}

- https://deafworldaroundyou.org/Stories

- https://www.ndcs.org.uk/deaf-child-worldwide/our-stories/visual-information-booklets-la unched-in-odisha-india/

- http://www.livebinders.com/b/2643652

- https://www.ndcs.org.uk/deaf-child-worldwide/information-and-resources/sign-language -resources/

\subsection{Evaluation criteria for programmes}

- https://www.oecd.org/dac/evaluation/daccriteriaforevaluatingdevelopmentassistance.ht m 


\section{References}

Bornstein MC, Hendricks C. (2013) Screening for developmental disabilities in developing countries. Soc Sci Med, 307-15.

Geers, A. (2003). Predictors of reading skill development in children with early cochlear implantation. 24(1), 59S-68S.

Harris, M., Terlektsi, E., \& Kyle, F. (2017). Literacy outcomes for primary school children who are deaf and hard of hearing: A cohort comparison study. 60(3), 701-711.

Haßler, B., Khalayleh, A., \& McBurnie, C. (2020). A five-part education response to the COVID-19 pandemic (EdTech Hub Helpdesk Response No. 5). https://doi.org/10.5281/zenodo.3756012

Howell, J. J. (2003). Helping one deaf student develop content literacy skills: An action research report. 25(1), 23-27.

Lang, H. G., \& Steely, D. (2003). Web-based science instruction for deaf students: What research says to the teacher. Instructional Science, 31(4/5), 277-298.

Lewis, M. S. J. (2001). Television literacy: comprehension of program content using closed captions for the deaf. Journal of Deaf Studies \& Deaf Education, 6(1), 43-54. doi:10.1093/deafed/6.1.43

Long, G. L., Marchetti, C., \& Fasse, R. (2011). The Importance of Interaction for Academic Success in Online Courses with Hearing, Deaf, and Hard-of-Hearing Students. International Review of Research in Open and Distance Learning, 12(6), 1-19.

Mactaggart, I. (2013). The key informant child disability project in Bangladesh and Pakistan: main report 2013.

Mandke, K., \& Chandekar, P. (2019). Deaf Education in India. In Deaf Education Beyond the Western World: Context, Challenges (pp. 261).

McKeown, C., \& McKeown, J. (2019). Accessibility in Online Courses: Understanding the Deaf Learner. TechTrends, 63(5), 506-513. doi:http://dx.doi.org/10.1007/s11528-019-00385-3

Mushtaq, R., \& Reba, A. J. D. (2017). Capacity Building Initiatives for Hearing-Impaired Children's Education in Khyber Pakhtunkhwa, Pakistan. 12(1).

Northern, J. L., \& Downs, M. P. (2002). Hearing in children: Lippincott Williams \& Wilkins.

Pappas, M. A., Demertzi, E., Papagerasimou, Y., Koukianakis, L., Kouremenos, D., Loukidis, I., \& Drigas, A. S. (2018). E-Learning for Deaf Adults from a User-Centered Perspective. Education Sciences, 8, 1-15. 
Parton, B. S. (2016). Video Captions for Online Courses: Do YouTube's Auto-Generated Captions Meet Deaf Students' Needs? Journal of Open, Flexible and Distance Learning, 20(1), 8-18.

Skutnabb-Kangas, T. J. E. i. i. d. c. (2008). Bilingual education and sign language as the mother tongue of deaf children. 75-94.

Uus, K., \& Bamford, J. (2006). Effectiveness of Population-Based Newborn Hearing Screening in England: Ages of Interventions and Profile of Cases. Pediatrics, 117 (5) e887-e893; DOI: https://doi.org/10.1542/peds.2005-1064.

World Health Organization. World Report on Disability/World Health Organization [and] The World Bank, ed. B. World. Geneva: World Health Organization, 2011.

Yoon, J.-o., \& Kim, M. (2011). The effects of captions on deaf students' content comprehension, cognitive load, and motivation in online learning American Annals of the Deaf, 156(3), 283-289.

Zirzow, N. K. (2015). Signing Avatars: Using Virtual Reality to Support Students with Hearing Loss. Rural Special Education Quarterly, 34(3), 33-36. 